\title{
Suppressing antagonistic bioengineering feedbacks doubles restoration success
}

\author{
Wouter Suykerbuyk,,${ }^{1,2,6}$ Tueerd J. Bouma, ${ }^{2}$ Tuisse van der Heide, ${ }^{3}$ Cornelia Faust,${ }^{2}$ Laura L. Govers, ${ }^{1}$ \\ Wim B. J. T. Giesen, ${ }^{1,4}$ Dick J. De Jong, ${ }^{5}$ and Marieke M. van Katwijk ${ }^{1}$ \\ ${ }^{1}$ Department of Environmental Science, Institute for Water and Wetland Research, Faculty of Science, Radboud University Nijmegen, \\ P.O. Box 9010, 6500 GL Nijmegen, The Netherlands \\ ${ }^{2}$ Department of Spatial Ecology, Royal Netherlands Institute for Sea Research (NIOZ), P.O. Box 140, \\ 4400 AC Yerseke, The Netherlands \\ ${ }^{3}$ Community and Conservation Ecology Group, Centre for Ecological and Evolutionary Studies (CEES), Groningen University, \\ P.O. Box 11103, 9700 CC Groningen, The Netherlands \\ ${ }^{4}$ Euroconsult Mott MacDonald, P.O. Box 441, 6800 AK Arnhem, The Netherlands \\ ${ }^{5}$ Ministry of Infrastructure and Environment, Rijkswaterstaat, Zeeland Department, P.O. Box 5014, \\ 4330 KA Middelburg, The Netherlands
}

Abstract. In a seagrass restoration project, we explored the potential for enhancing the restoration process by excluding antagonistic engineering interactions (i.e., biomechanical warfare) between two ecosystem engineers: the bioturbating lugworm Arenicola marina and the sediment-stabilizing seagrass Zostera noltii Hornem. Applying a shell layer underneath half of our seagrass transplants successfully reduced adult lugworm density by over $80 \%$ and reduced lugworm-induced microtopography (a proxy for lugworm disturbance) at the wavesheltered site. At the wave-exposed site adult lugworm densities and microtopography were already lower than at the sheltered site but were further reduced in the shell-treated units. Excluding lugworms and their bioengineering effects corresponded well with a strongly enhanced seagrass growth at the wave-sheltered site, which was absent at the exposed site. Enhanced seagrass growth in the present study was fully assigned to the removal of lugworms' negative engineering effects and not to any (indirect) evolving effects such as an altered biogeochemistry or sediment-stabilizing effects by the shell layer. The context-dependency implies that seagrass establishment at the exposed site is not constrained by negative ecosystem-engineering interactions only, but also by overriding physical stresses causing poor growth conditions. Present findings underline that, in addition to recent emphasis on considering positive (facilitating) interactions in ecological theory and practice, it is equally important to consider negative engineering interactions between ecosystem-engineering species. Removal of such negative interactions between ecosystem-engineering species can give a head start to the target species at the initial establishment phase, when positive engineering feedbacks by the target species on itself are still lacking. Though our study was carried out in a marine environment with variable levels of wave disturbance, similar principles may be expected to apply to other ecosystems that are inhabited by ecosystem engineers.

Key words: Arenicola marina; bioturbation; conservation; Eastern Scheldt estuary, southwestern Netherlands; ecosystem engineers; exclusion; lugworm; negative feedbacks; restoration; seagrass meadow; Zostera noltii Hornem.

\section{INTRODUCTION}

Approximately $30-50 \%$ of the Earth's coastal ecosystems have been severely degraded in the last decades, often due to anthropogenic disturbances such as eutrophication or overexploitation (Orth et al. 2006, Barbier et al. 2008). Even though these areas make up

Manuscript received 7 September 2011; revised 23 January 2012; accepted 30 January 2012. Corresponding Editor: C. B. Craft.

${ }^{6}$ Address for correspondence: Department of Environmental Science, Radboud University Nijmegen, P.O. Box 9010, 6500 GL Nijmegen, The Netherlands.

E-mail: wouter.suykerbuyk@nioz.nl just $4 \%$ of the Earth's total surface, systems such as salt marshes, coral reefs, and seagrass meadows are of great economic and ecological importance because large human populations depend on them for storm buffering, fisheries, and enhanced water quality (Orth et al. 2006, Barbier et al. 2008). Moreover, they serve as key habitat in the life cycles of many marine animal species. Although these ecosystems were initially considered highly resilient to human disturbance, we now know that most coastal ecosystems do not respond linearly to change, but may often collapse without warning (Silliman et al. 2005, van der Heide et al. 2007, Hughes et al. 2010). It has also emerged that recovery or restoration of 
coastal ecosystems is extremely difficult (Bakker et al. 2002, Orth et al. 2006, Halpern et al. 2007, Omori 2010).

Various studies have shown that sudden collapse and lack of recovery in coastal ecosystems may follow alternative stable state behavior and can be attributed to disturbance of positive feedback mechanisms (e.g., van de Koppel et al. 2001, van der Heide et al. 2007). Such feedbacks typically arise from the ability of the foundation species (e.g., corals, seagrasses, reef-forming shellfish, marsh plants) to ameliorate environmental stress (i.e., "ecosystem engineering") (e.g., Jones et al. 1994, Madsen et al. 2001). Because these (self-) facilitation mechanisms typically act above a certain density or size (e.g., van der Heide et al. 2007, 2008, Bouma et al. 2009), coastal ecosystems are prone to threshold behavior. The ecosystem seems stable above the threshold size or density, while recovery and restoration are nearly impossible when the threshold is not bridged (Hobbs and Norton 1996, Halpern et al. 2007, Suding and Hobbs 2009).

Today, (self-) facilitation and positive feedbacks are well recognized as important factors to consider for coastal ecosystem conservation and restoration (Crain and Bertness 2006, Halpern et al. 2007). The potential role of negative interactions between contrasting ecosystem engineers in restoration efforts has recently been neglected, despite the early recognition of its potential importance in marine habitats (see review in Peterson 1980, 1991). For example, this has been shown for the negative effect of deposit feeders on filter feeders by making sediment more erosive, causing filter feeding to be hampered by more turbid water (i.e., trophic group amensalism; Rhoads and Young 1970). Several studies have also demonstrated that negative interactions between benthos and vegetation can be very strong (Philippart 1994, Hughes et al. 2000, Hughes and Paramor 2004, Siebert and Branch 2006, Berkenbusch et al. 2007, van Wesenbeeck et al. 2007). For instance, "biomechanical warfare" between ecosystem-engineering salt marsh vegetation and infauna can cause a bimodal species distribution on the salt marsh-mudflat interface, as bioturbation prevented plant colonization in the invertebrate-dominated state and invertebrates were excluded by sediment compaction in the plantdominated state (van Wesenbeeck et al. 2007).

Meadows of the seagrass Zostera noltii Hornem are notoriously hard to restore, and initial establishment is especially difficult as positive feedbacks are still lacking (i.e., Byers et al. 2006, van der Heide et al. 2007, van Katwijk et al. 2009). Historically, Zostera meadows are found to co-occur with the bioturbating lugworm Arenicola marina (Jacobs et al. 1983), though they may encounter negative worm effects (i.e., Philippart 1994, Reise and Kohlus 2008). At present, in some areas of northwestern Europe the Zostera noltii biomass distribution appears to be correlated with the presence of shallow layers of clay, compressed peat, or shells that naturally exclude bioturbating lugworms (Reise 2002, Reise and Kohlus 2008; D. J. de Jong, W. B. J. T. Giesen, M. M. van Katwijk, and W. Suykerbuyk, personal observation in Scheldt Estuary). Moreover, settlement of Zostera noltii has been observed in plots where lugworms were excluded for experimental purposes (Reise 1983, Reise and Kohlus 2008). The absence of seagrass recovery on former seagrass grounds that are now inhabited by lugworms, despite the improved water quality with respect to increased transparency and reduced nutrient concentrations over the last decades, may suggest that the lugworm presence and/or activity may hamper recolonization by seagrass within our study area.

In this study we test to what extent restoration of Zostera noltii meadows at formerly suitable seagrass habitats would benefit from removal of negative effects by the bioturbating lugworm Arenicola marina and how this depends on abiotic conditions (sheltered vs. wave exposed). Removal of these negative ecosystem-engineering effects on initial seagrass establishment was tested in a large-scale Zostera noltii restoration by comparing sod transplantations with and without lugworm reduction by means of a shallow shell layer (cf. Reise 2002). To test the general relevance of excluding such negative engineering interactions, we tested this method under contrasting abiotic conditions (wave exposed vs. wave sheltered) that may cause other sources of sediment disturbance. We hypothesize that minimizing lugworm-induced sediment disturbance will enhance seagrass growth, unless other sources of abiotic stress cause sediment disturbance.

\section{Methods \\ Study area}

Our experiment was performed in the Eastern Scheldt estuary (southwestern Netherlands), a former arm in the river Scheldt delta (Fig. 1A). After a severe flood in 1953, the estuary was heavily engineered to secure safety against flooding: freshwater input openings in the eastern part of the estuary were cut off by dams and the estuary mouth in the west was partially closed by a storm surge barrier. Since then, the system has changed (e.g., Louters et al. 1998), and the extensive seagrass meadows (up to 1000 ha) have decreased during the building of these so-called Delta Works. More surprisingly, this seagrass decline has persisted long after the completion of the Delta Works and is ongoing today, despite the higher transparency of the water column and lower nutrient loading.

Presently, only several dozen hectares of the seagrass Zostera noltii Hornem remain (data from the Dutch Ministry of Infrastructure and the Environment), which appear to be concentrated on relatively stable sediments without lugworm presence (e.g., natural shell layers, heavy clay from former dikes, or salt marsh remnants; D. J. de Jong, W. B. J. T. Giesen, M. M. van Katwijk, and W. Suykerbuyk, personal observations). Exact 
mechanistic causes of this massive and persistent seagrass decline have not yet been identified. It has been observed that the lugworm relief had increased at many intertidal former seagrass locations (D. J. de Jong, W. B. J. T. Giesen, M. M. van Katwijk, and W. Suykerbuyk, personal observations). No previous seagrass transplantation or restoration efforts have been performed in the Eastern Scheldt estuary. Renewal of the stone cladding of the defense walls requires mitigating measures for the directly endangered seagrass that follow European Union regulations. This led to the present transplantation project.

\section{Experimental set-up}

A total of $441 \mathrm{~m}^{2}$ of native Zostera noltii Hornem sods (196 sods of $1.5 \times 1.5 \mathrm{~m}$ ) with a vegetation cover ranging from $10 \%$ to $70 \%$ (sod vegetation cover, $33 \% \pm$ $2 \%$ [mean $\pm \mathrm{SE}]$ ) were transplanted to two tidal flats, one sheltered (Krabbenkreek flat) and one relatively more exposed (Slikken van den Dortsman), in the Eastern Scheldt estuary early in the growing season (June 2007) (Fig. 1B, C). Sods were mechanically harvested in custom-made wooden boxes from a natural meadow at the donor site Slikken van Viane. They were protected against desiccation during transport and replanted within $24 \mathrm{~h}$ to 28 plots divided over the sheltered (16) and exposed (12) sites. Plots were distributed evenly $10 \mathrm{~m}$ apart in rows at an average emerging time of 50-60\% (Fig. 1B, C). To test the effect of plot size, plots consisted of either five or nine sods placed in a checkerboard configuration (Fig. 1D). Planting configurations were evenly applied over the control and exclusion plots at both locations (Fig. 1B, C). In every second transplantation plot, adult lugworms (Arenicola marina) were excluded by placing a $10 \mathrm{~cm}$ thick shell layer (local cockle shell fragments with a diameter of $4 \mathrm{~cm}$ ) at a depth of $8-18 \mathrm{~cm}$ below the sediment surface, both underneath the seagrass sods and the surrounding plot sediment (Fig. 1E, F) (after Reise 2002). In the control plots, sediment was similarly removed and replaced to adjust for sediment handling.

Basic transplant characteristics (i.e., plant coverage and area), as well as lugworm and other biological parameters, were monitored at monthly intervals during the growing season from June until October. The area covered by seagrass (in square meters) is considered to be the main indicator for transplantation success (Schanz and Asmus 2003), with area being measured and cover being estimated by eye using a $25 \times 25 \mathrm{~cm}$ grid and cross-checking between workers. Lugworm fecal cast counts per area were used as a quantitative proxy for the numbers of worms present (cf. Farke and Berghuis 1979, Flach and Beukema 1994). Juvenile and adult lugworms were divided by the diameter of the cylindrical-shaped cast; rule of thumb: juvenile < diameter cast $1 \mathrm{~mm}<$ adult. In order to prevent severe underestimation of lugworm numbers, cast counts were not performed on a rainy day or prior to $2 \mathrm{~h}$ after the transplants emerged from the water (sensu Cadee 1976). Lugworm-induced microtopography (also referred to as lugworm relief) was measured as the vertical height difference between a lugworms' pit and adjacent mound. This parameter was used as a simple integrative proxy for the potential negative engineering effects of lugworm-induced sediment disturbance (e.g., direct burial, unearthing rhizomes, and sediment instability) on seagrass survival, as it accounts for size and activity differences between local lugworm communities and can easily be compared across sites with other sources of sediment disturbance such as wave exposure.

\section{Sediment characteristics}

Additional measurements of pore water nutrients (alkalinity, $\mathrm{pH}, \mathrm{NO}_{3}{ }^{-}, \mathrm{NH}_{4}{ }^{+}$and ortho- $\mathrm{PO}_{4}$, sheltered sites only) and sediment composition (grain size distribution and organic content, both sites) were performed just after maximum seagrass biomass and area were reached in the growing season (early September). Alkalinity (by titration with $0.01 \mathrm{~mol} / \mathrm{L}$ $\mathrm{HCl}$ to $\mathrm{pH}$ 4.2; Lamers et al. 1998) and $\mathrm{pH}$ were determined directly after sampling, whereupon samples were frozen $\left(-20^{\circ} \mathrm{C}\right)$ until further analysis. Ammonia and ortho-phosphate concentrations were measured colorimetrically on an auto-analyzer (Bran+Luebbe, Almere, The Netherlands), using hypochlorite (Berthelot reaction) and ammonium-molybdate, respectively. Organic matter content in freeze-dried sediments (upper $5 \mathrm{~cm}$ ) was estimated as mass loss by ignition at $550^{\circ} \mathrm{C}$ after acidifying samples with $\mathrm{HCl}$. Grain size distribution on the same sediment sieved over $1 \mathrm{~mm}$ was measured by laser diffraction on a particle sizer (Malvern, Worcestershire, UK).

\section{Statistical analysis}

All results are summarized as means \pm SE. In advance of statistical analysis, data were checked for normality and if necessary transformed (Table 1). As planting configuration had no effect on seagrass survival (data not shown), plots are treated as replicates in further statistical analysis. Differences between transplantation sites and anti-lugworm treatments were analyzed using ANOVA with treatment nested in location, followed by post hoc Tukey's honestly significant differences (HSD) multiple means comparison tests at the 0.05 confidence limit. Effects of control and shell treatment on pore water and sediment data were tested by independentsamples $t$ test. All tests were performed using Statistica (StatSoft, Tulsa, Oklahoma, USA).

\section{REsults}

Shell layers successfully reduced the mean numbers of adult lugworms at both the sheltered $(P<0.01)$ and the exposed $(P<0.01)$ transplantation sites (Fig. 2A). Although initially the ambient number of lugworms at the exposed site was almost 2.5 times lower than that at the sheltered location, the proportional reduction of 

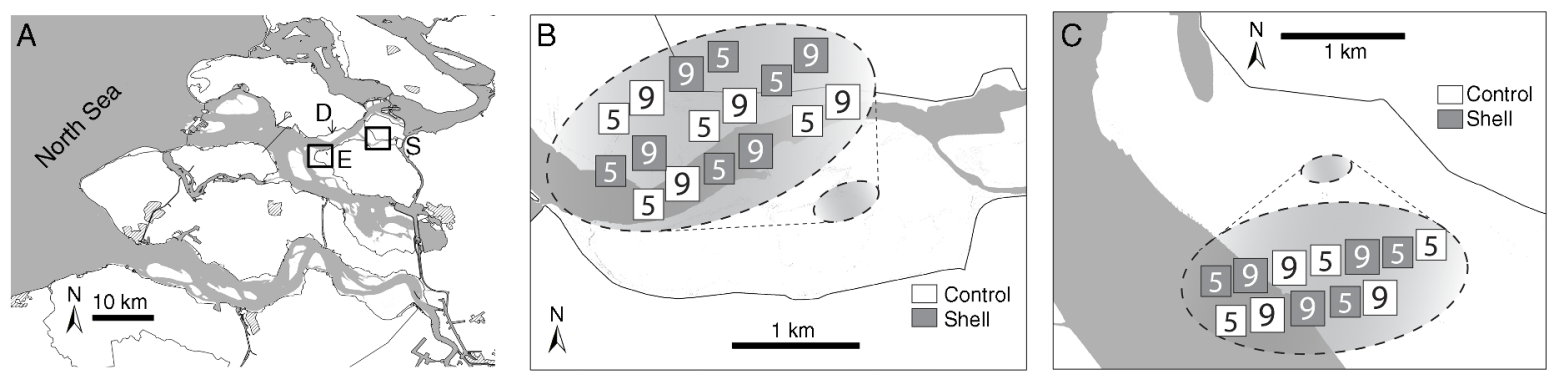

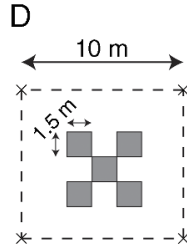

Five patches

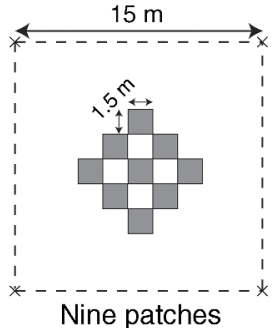

$E$

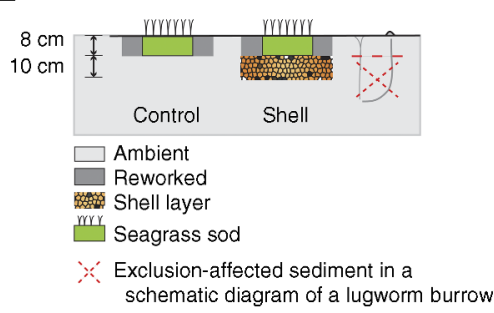

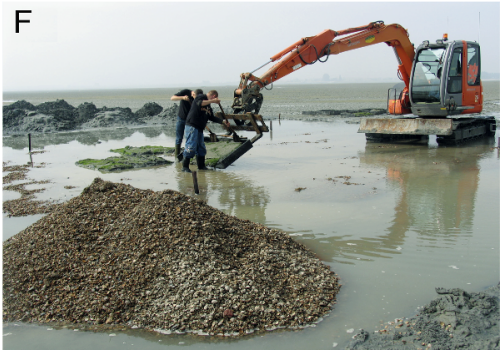

FIG. 1. (A) Location of the study areas in the southwest delta area of The Netherlands. Letters indicate the donor site (D) and the wave-exposed (E) and sheltered (S) Zostera noltii seagrass transplantation sites in the Eastern Scheldt estuary. (B, C) Detailed top view of (B) the wave-sheltered Krabbenkreek flats and (C) the wave-exposed Slikken van den Dortsman flats; shading indicates anti-lugworm (Arenicola marina) treatments (application of shells), and numbers indicate planting configuration. (D) Schematic top view of plots with two different planting densities (five and nine patches), their configuration (a checkerboard pattern), and the plot area that was reworked for the anti-lugworm treatment. (E) Schematic cross section of the plots indicating the manner in which sediments are reworked and organized. Colors indicate different sediment origins or treatments. At the far right is a schematic of a lugworm burrow indicating the significance of the anti-lugworm treatment on lugworm burrowing. (F) Large-scale seagrass transplantation in progress at the sheltered site. Shells applied to exclude lugworms are seen in the foreground. Placement of seagrass sod on the shell treatment is seen in the background.

adult worms due to the shell layer was of the same order of magnitude ( $81.3 \%$ vs. $86.8 \%$ for sheltered and exposed, respectively). The shell treatment significantly promoted $(P<0.05)$ settlement of juvenile lugworms in the absence of adult worms at both sites $(277.8 \%$ vs. $290.4 \%$ increase for shell-treated compared to control plots, respectively, both at wave-sheltered and waveexposed sites; Fig. 2B). Adult lugworm numbers remained stable during at least three more years (data not shown).

Lugworm-induced microtopography, and thereby the negative engineering effect of lugworms on seagrass, was significantly reduced by the shell treatment at the sheltered location $(P<0.01$; Fig. 2C). Exclusion plots could be easily recognized by the reduction of this characteristic pit and mound landscape. At the exposed site, similar anti-lugworm measures and their proportional effects on lugworm numbers resulted in relatively higher reduction of lugworm relief between control and treated plots of the exposed site compared to the sheltered site (50.5\% vs. $37.0 \%$ reduction, respectively). Surprisingly, this reduction in relief was not found significantly different from that found at the sheltered site.

TABLE 1. Results of nested ANOVA on the number of adult and juvenile lugworms (Arenicola marina), their induced microtopography, and the related seagrass (Zostera noltii) area detected at each treated plot on two tidal flats.

\begin{tabular}{|c|c|c|c|c|c|c|c|}
\hline Dependent variable & Transformation & Factor & SS & df & MS & $F$ & $P$ \\
\hline \multirow[t]{3}{*}{ Adult lugworms } & \multirow[t]{3}{*}{ square root } & location & 23.14 & 1 & 23.14 & 8.28 & 0.006 \\
\hline & & treatment(location) & 122.74 & 2 & 61.37 & 21.96 & $<0.001$ \\
\hline & & error & 120.16 & 43 & 2.79 & & \\
\hline \multirow[t]{3}{*}{ Juvenile lugworms } & \multirow[t]{3}{*}{ fourth root } & location & 1.75 & 1 & 1.75 & 1.53 & 0.223 \\
\hline & & treatment(location) & 14.39 & 2 & 7.19 & 6.29 & 0.004 \\
\hline & & error & 49.21 & 43 & 1.14 & & \\
\hline \multirow[t]{3}{*}{ Lugworm relief } & \multirow[t]{3}{*}{ fourth root } & location & 128.31 & 1 & 128.31 & 22.84 & $<0.001$ \\
\hline & & treatment(location) & 71.81 & 2 & 35.91 & 6.39 & 0.004 \\
\hline & & error & 235.91 & 42 & 5.62 & & \\
\hline \multirow[t]{3}{*}{ Seagrass area } & \multirow[t]{3}{*}{$\log$} & location & 1.23 & 1 & 1.23 & 4.12 & 0.054 \\
\hline & & treatment(location) & 3.67 & 2 & 1.84 & 6.13 & 0.007 \\
\hline & & error & 7.19 & 24 & 0.30 & & \\
\hline
\end{tabular}

Note: The study was conducted in the southwest delta area of The Netherlands. 

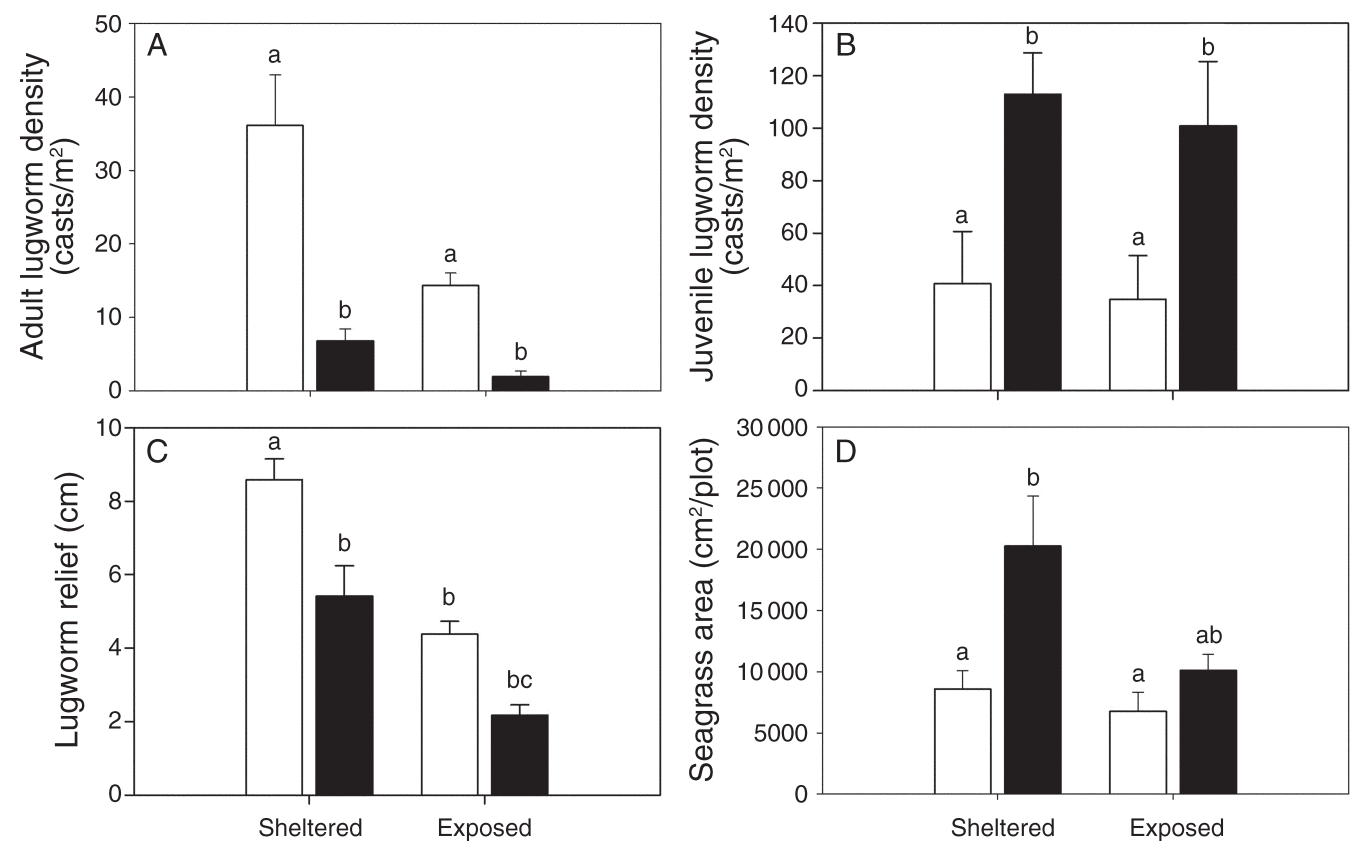

FIG. 2. Effects of hydrodynamic forcing (wave sheltered vs. wave exposed) and lugworm exclusion method (control in white vs. exclusion in black) on density of (A) adult and (B) juvenile lugworms (counts of fecal casts), (C) lugworm relief (lugworm-induced microtopography, used as proxy for lugworm disturbance), and (D) seagrass area per plot (used as proxy for restoration success). Data are from 17 and 18 July 2008, 13 months after transplantation. Bars represent mean + SE. Different letters above bars indicate significant differences (Tukey's HSD, $P<0.05$ ).

Although reduction of lugworm microtopography was comparable at both sites, surprisingly no such comparable effects on seagrass growth were found. That is, at the sheltered site, seagrass growth was significantly promoted in plots that excluded Arenicola by shells as compared to the control plots $(P<0.05$; Fig. 2D) (data 17 and 18 July 2008). However, no such difference was found at the exposed transplantation site, where seagrass growth was low both in the presence and absence of worm exclusion. Seagrass growth responses at the sheltered site could not be ascribed to shell layer effects on sediment and pore water characteristics, as these were unaffected (Table 2) except for a slightly lower median grain size $\left(\mathrm{D} 50_{\mathrm{SED}}\right)$ in the exposed lugworm-exclusion plots $\left(t_{14}=2.38, P<0.05\right)$. Planting configuration (five or nine sods) had no effect on seagrass survival at either site at any point in time (data not shown).

\section{DisCUSSION}

The use of facilitative interactions is now a common recommendation in restoration and conservation efforts, and ecosystem engineers causing such interactions are increasingly considered to be conservation and restoration target species (Boogert et al. 2006, Byers et al. 2006, Crain and Bertness 2006, Halpern et al. 2007). Surprisingly, however, these papers neglect the potential restoration benefits of the removal of negative interactions originating from ecosystem engineers, despite the fact that such interactions can play an important role in marine habitats (Rhoads and Young 1970, Philippart 1994, Hughes et al. 2000, Hughes and Paramor 2004, Siebert and Branch 2006, Berkenbusch et al. 2007, van Wesenbeeck et al. 2007). In this study, we show that suppressing such negative ecosystem-engineering effects could be a useful approach in restoration and conservation efforts by giving at least a better start during the initial establishment phase. Using the seagrass (biostabilizer)-lugworm (biodestabilizer) interaction as a model system, we showed that seagrass growth was significantly enhanced by excluding lugworms in a lugwormdominated area. Removing negative engineering interactions may be especially important for reestablishing those species whose initial establishment is hampered by thresholds but who subsequently benefit from selffacilitating positive feedbacks. The latter is clearly the case in seagrass (van der Heide et al. 2007, 2011, van Katwijk et al. 2010).

Enhanced seagrass growth in the present study was fully assigned to the lugworm exclusion and not to any (indirect) evolving effects such as an altered biogeochemistry (Table 2) or sediment-stabilizing effects by the shell layer. From previous studies on Zostera it is known that sediment stabilization improves success at relatively exposed locations (van Katwijk and Hermus 2000, Reise and Kohlus 2008), but that this is not always the case at sheltered locations (van Katwijk and Hermus 2000). In our study the reverse holds true: the success was only promoted at sheltered sites. Therefore, this explanation does not hold for our situation. At the relatively exposed 
TABLE 2. Sediment and pore water composition in control and exclusion (shell) plots at sheltered and exposed transplantation sites.

\begin{tabular}{|c|c|c|c|c|c|}
\hline \multirow[b]{2}{*}{ Parameter } & \multirow[b]{2}{*}{ Treatment } & \multicolumn{2}{|c|}{ Sheltered } & \multicolumn{2}{|c|}{ Exposed } \\
\hline & & Mean & $\mathrm{SE}$ & Mean & SE \\
\hline \multirow[t]{2}{*}{$\mathrm{D} 50_{\mathrm{SED}}(\mu \mathrm{m})$} & control & 159.13 & 8.54 & 179.08 & 1.19 \\
\hline & shell & 168.70 & 5.74 & 175.40 & 0.98 \\
\hline \multirow[t]{2}{*}{ Org $C_{\text {SED }}(\%)$} & control & 1.27 & 0.13 & 0.55 & 0.09 \\
\hline & shell & 1.04 & 0.14 & 0.69 & 0.12 \\
\hline \multirow[t]{2}{*}{$\mathrm{NH}_{4}(\mu \mathrm{mol} / \mathrm{L})$} & control & 91.82 & 11.18 & $\cdots$ & $\cdots$ \\
\hline & shell & 104.17 & 13.15 & $\ldots$ & $\cdots$ \\
\hline \multirow{2}{*}{ ortho- $\mathrm{PO}_{4}(\mu \mathrm{mol} / \mathrm{L})$} & control & 13.14 & 2.62 & $\cdots$ & $\cdots$ \\
\hline & shell & 14.24 & 1.34 & $\ldots$ & $\ldots$ \\
\hline \multirow[t]{2}{*}{$\mathrm{pH}$} & control & 7.48 & 0.02 & $\cdots$ & $\cdots$ \\
\hline & shell & 7.49 & 0.03 & $\ldots$ & $\ldots$ \\
\hline \multirow[t]{2}{*}{ Alkalinity (meq/L) } & control & 2.75 & 0.12 & $\cdots$ & $\cdots$ \\
\hline & shell & 3.03 & 0.10 & $\ldots$ & $\ldots$ \\
\hline
\end{tabular}

Notes: Sampling was conducted in early September 2007, three months after transplantation. Significant differences between treated and untreated plots are indicated in bold ( $t$ test, $P<0.05$ ). Abbreviations are: D50 $0_{\text {SED }}$, median grain size of the sediment; Org $\mathrm{C}_{\mathrm{SED}}$, organic carbon fraction of the sediment. All other parameters refer to the pore water.

site no positive effect of lugworm exclusion on seagrass growth was found, although the proportional reduction of lugworm disturbance was comparable to that observed at the sheltered site. We expect this to be due to poorer growth conditions at the exposed site, due to direct physical disturbances by waves and currents (dislodgement or mechanical stress) or to indirect effects of increased hydrodynamics, such as increased sediment dynamics (resulting in burial or erosion) (e.g., Cabaço and Santos 2007; Han et al. 2012) or decreased epiphyte grazer densities (increasing algal overgrowth and thus light reduction for the seagrass plants) (Schanz and Asmus 2003). This indicates that excluding negative ecosystem-engineering interactions to initiate a population is only useful in areas where growth is not limited by other overriding (physical) stresses.

\section{Feasibility and long-term consequences of our method}

Our large-scale shell treatment proved to be a good measure for promoting initial seagrass establishment success by excluding adult lugworms and their negative effects, which is an important step in restoration. Extra costs for the application of a shell layer were $\sim 20 \%$ of the total transplantation costs. For restoration purposes, lugworm exclusion by shells has major advantages over using nets, as have been used in scientific studies on lugworm exclusion (Reise 1983, Philippart 1994, Volkenborn and Reise 2006). First, shells are natural material that can generally be easily obtained locally. Second, in contrast to nets as used by Volkenborn and Reise (2006), shell layers only exclude large lugworms and allow smaller ones to establish. This is advantageous because the full exclusion has several side effects, such as the accumulation of fine sediment and the blockage of interstitial pores causing enhanced nutrient and sulphide levels (Volkenborn et al. 2007) that may have negative effects on seagrass performance (i.e., Touchette and Burkholder 2000, Calleja et al. 2007).
The present approach of removing negative engineering interactions was specifically aimed at improving the initial establishment for ecosystems that are difficult to restore due to establishment thresholds, but can later maintain themselves by self-facilitating positive feedbacks. Maximal establishment is the first requirement to enhance long-term success. However, although the treatment most likely will continue to diminish negative engineering interactions over the long term (the shell layer will not easily get lost), this does not necessarily warrant long-term success. During winter, when lugworms are less active and seagrass is dormant, grazing or physical disturbances from storm-driven waves, freezing, and ice rafting may form a second bottleneck to meadow persistence and thus restoration success. Unfortunately, these processes appeared to be important at our restoration sites, as seagrass transplantation suffered large losses during subsequent winters. Still, during summers, the shell treatment had a consistent positive effect on seagrass survival and growth similar to that shown in Fig. 2. Present observations suggest that the proposed method of removing negative engineering interactions will be most beneficial in those areas where biological activity causing such interactions is the main driver restricting seagrass growth year round.

\section{Conclusions}

Dynamic ecosystems that do not respond linearly to changes but are characterized by threshold behavior (such as coastal ecosystems) are notoriously difficult to restore (Rapport et al. 1998, Hobbs et al. 2006, van der Heide et al. 2007, Suding and Hobbs 2009) and are also sensitive to environmental perturbations (Scheffer et al. 2001, Pascual and Guichard 2005). Thorough understanding of system feedbacks, criticalities, shifts, and thresholds is needed to predict and thereby prevent transitions toward a barren state (Pascual and Guichard 2005, Scheffer et al. 2009, Firn et al. 2010). We provide 
compelling experimental evidence demonstrating that exclusion of negative ecosystem-engineering interactions may be useful in initiating the reestablishment of those species whose initial establishment is hampered by thresholds but who subsequently benefit from selffacilitating positive feedbacks. Present findings underline that in addition to the recent growing awareness of the need to consider positive (facilitating) interactions in ecological theory (i.e., Bruno et al. 2003, Brooker and Callaway 2009) and ecological conservation and restoration projects (Byers et al. 2006, Crain and Bertness 2006, Halpern et al. 2007, van Katwijk et al. 2009), it is equally important to also consider negative engineering interactions between ecosystem-engineering species in restoration projects. This result reemphasizes and (by specifically focusing on negative engineering interactions) extends a wealth of older theory (Rhoads et al. 1970, Peterson 1980, 1991, Reise 1985, Wilson 1991). Similar to positive feedbacks, such negative engineering interactions may also cause threshold dynamics. Though our study was carried out in a marine environment, similar principles may be expected to apply to other ecosystems dominated by ecosystem engineers (Rietkerk et al. 2004, Scheffer et al. 2009).

\section{ACKNOWLEDGMENTS}

We gratefully acknowledge Paul Giesen, Kris Giesen, Martin Versteeg, Tine Driessen, Christiaan Stouten, and Roy van de Voort for their technical and/or management support, and Jan Hendriks, Rob Leuven, and Alan Ziegler for valuable comments on earlier versions of the manuscript. We acknowledge B. T. L. Bruinisse for the successful execution of the transplants and Projectbureau Zeeweringen (executive part of Dutch Ministry of Infrastructure and the Environment) for funding this work.

\section{Literature Cited}

Bakker, J. P., P. Esselink, K. S. Dijkema, W. E. van Duin, and D. J. de Jong. 2002. Restoration of salt marshes in the Netherlands. Hydrobiologia 478:29-51.

Barbier, E. B., et al. 2008. Coastal ecosystem-based management with nonlinear ecological functions and values. Science 319:321-323.

Berkenbusch, K., A. A. Rowden, and T. E. Myers. 2007. Interactions between seagrasses and burrowing ghost shrimps and their influence on infaunal assemblages. Journal of Experimental Marine Biology and Ecology 341:70-84.

Boogert, N. J., D. M. Paterson, and K. N. Laland. 2006. The implications of niche construction and ecosystem engineering for conservation biology. BioScience 56:570-578.

Bouma, T. J., M. Friedrichs, B. K. van Wesenbeeck, S. Temmerman, G. Graf, and P. M. J. Herman. 2009. Density-dependent linkage of scale-dependent feedbacks: a flume study on the intertidal macrophyte Spartina anglica. Oikos 118:260-268.

Brooker, R. W., and R. M. Callaway. 2009. Facilitation in the conceptual melting pot. Journal of Ecology 97:1117-1120.

Bruno, J. F., J. J. Stachowicz, and M. D. Bertness. 2003. Inclusion of facilitation into ecological theory. Trends in Ecology and Evolution 18:119-125.

Byers, J. E., K. Cuddington, C. G. Jones, T. S. Talley, A. Hastings, J. G. Lambrinos, J. A. Crooks, and W. G. Wilson. 2006. Using ecosystem engineers to restore ecological systems. Trends in Ecology and Evolution 21:493-500.
Cabaço, S., and R. Santos. 2007. Effects of burial and erosion on the seagrass Zostera noltii. Journal of Experimental Marine Biology and Ecology 340:204-212.

Cadee, G. C. 1976. Sediment reworking by Arenicola marina on tidal flats in Dutch Wadden Sea. Netherlands Journal of Sea Research 10:440-460.

Calleja, M. L., N. Marba, and C. M. Duarte. 2007. The relationship between seagrass (Posidonia oceanica) decline and sulfide porewater concentration in carbonate sediments. Estuarine, Coastal and Shelf Science 73:583-588.

Crain, C. M., and M. D. Bertness. 2006. Ecosystem engineering across environmental gradients: implications for conservation and management. BioScience 56:211-218.

Farke, H., and E. M. Berghuis. 1979. Spawning, larval development and migration of Arenicola marina under field conditions in the western Wadden Sea. Netherlands Journal of Sea Research 13:529-535.

Firn, J., A. P. N. House, and Y. M. Buckley. 2010. Alternative states models provide an effective framework for invasive species control and restoration of native communities. Journal of Applied Ecology 47:96-105.

Flach, E. C., and J. J. Beukema. 1994. Density-governing mechanisms in populations of the lugworm Arenicola-marina on tidal flats. Marine Ecology Progress Series 115:139-149.

Halpern, B. S., B. R. Silliman, J. D. Olden, J. P. Bruno, and M. D. Bertness. 2007. Incorporating positive interactions in aquatic restoration and conservation. Frontiers in Ecology and the Environment 5:153-160.

Han, Q., T. J. Bouma, F. G. Brun, W. Suykerbuyk, and M. M. van Katwijk. 2012. Resilience of Zostera noltii to burial and erosion disturbances. Marine Ecology Progress Series 449:133-143.

Hobbs, R. J., et al. 2006. Novel ecosystems: theoretical and management aspects of the new ecological world order. Global Ecology and Biogeography 15:1-7.

Hobbs, R. J., and D. A. Norton. 1996. Towards a conceptual framework for restoration ecology. Restoration Ecology 4:93-110.

Hughes, R. G., D. Lloyd, L. Ball, and D. Emson. 2000. The effects of the polychaete Nereis diversicolor on the distribution and transplanting success of Zostera noltii. Helgoland Marine Research 54:129-136.

Hughes, R. G., and O. A. L. Paramor. 2004. On the loss of saltmarshes in south-east England and methods for their restoration. Journal of Applied Ecology 41:440-448.

Hughes, T. P., N. A. J. Graham, J. B. C. Jackson, P. J. Mumby, and R. S. Steneck. 2010. Rising to the challenge of sustaining coral reef resilience. Trends in Ecology and Evolution 25:633-642.

Jacobs, R., H. H. Hegger, and A. Raswillems. 1983. Seasonalvariations in the structure of a Zostera community on tidal flats in the SW Netherlands, with special reference to the benthic fauna. Proceedings of the Koninklijke Nederlandse Akademie Van Wetenschappen Series C, Biological and Medical Sciences 86:347-375.

Jones, C. G., J. H. Lawton, and M. Shachak. 1994. Organisms as ecosystem engineers. Oikos 69:373-386.

Lamers, L. P. M., H. B. M. Tomassen, and J. G. M. Roelofs. 1998. Sulfate-induced entrophication and phytotoxicity in freshwater wetlands. Environmental Science and Technology 32:199-205.

Louters, T., J. H. van den Berg, and J. P. M. Mulder. 1998. Geomorphological changes of the Oosterschelde tidal system during and after the implementation of the delta project. Journal of Coastal Research 14:1134-1151.

Madsen, J. D., P. A. Chambers, W. F. James, E. W. Koch, and D. F. Westlake. 2001. The interaction between water movement, sediment dynamics and submersed macrophytes. Hydrobiologia 444:71-84.

Omori, M. 2010. Degradation and restoration of coral reefs: experience in Okinawa, Japan. Marine Biology Research 7:312. 
Pascual, M., and F. Guichard. 2005. Criticality and disturbance in spatial ecological systems. Trends in Ecology and Evolution 20:88-95.

Peterson, C. H. 1980. Approaches to the study of competition in benthic communities in soft sediments. Pages 291-302 in V. Kennedy, editor. Estuarine perspectives. Academic Press, New York, New York, USA.

Peterson, C. H. 1991. Intertidal zonation of marine-invertebrates in sand and mud. American Scientist 79:236-249.

Philippart, C. J. M. 1994. Interactions between Arenicola marina and Zostera noltii on a tidal flat in the Wadden Sea. Marine Ecology Progress Series 111:251-257.

Rapport, D. J., W. G. Whitford, and M. Hilden. 1998. Common patterns of ecosystem breakdown under stress. Environmental Monitoring and Assessment 51:171-178.

Reise, K. 1983. Experimental removal of lugworms from marine sand affects small zoobenthos. Marine Biology 74:327-332.

Reise, K. 1985. Tidal flat ecology: an experimental approach to species interactions. Springer Verlag, New York, New York, USA.

Reise, K. 2002. Sediment mediated species interactions in coastal waters. Journal of Sea Research 48:127-141.

Reise, K., and J. Kohlus. 2008. Seagrass recovery in the northern Wadden Sea? Helgoland Marine Research 62:7784.

Rhoads, D. C., and D. K. Young. 1970. Influence of depositfeeding organisms on sediment stability and community trophic structure. Journal of Marine Research 28:150-178.

Rietkerk, M., S. C. Dekker, P. C. de Ruiter, and J. van de Koppel. 2004. Self-organized patchiness and catastrophic shifts in ecosystems. Science 305:1926-1929.

Schanz, A., and H. Asmus. 2003. Impact of hydrodynamics on development and morphology of intertidal seagrasses in the Wadden Sea. Marine Ecology Progress Series 261:123-134.

Scheffer, M., J. Bascompte, W. A. Brock, V. Brovkin, S. R. Carpenter, V. Dakos, H. Held, E. H. van Nes, M. Rietkerk, and G. Sugihara. 2009. Early-warning signals for critical transitions. Nature 461:53-59.

Scheffer, M., S. Carpenter, J. A. Foley, C. Folke, and B. Walker. 2001. Catastrophic shifts in ecosystems. Nature 413:591-596.

Siebert, T., and G. M. Branch. 2006. Ecosystem engineers: Interactions between eelgrass Zostera capensis and the sandprawn Callianassa kraussi and their indirect effects on the mudprawn Upogebia africana. Journal of Experimental Marine Biology and Ecology 338:253-270.

Silliman, B. R., J. van de Koppel, M. D. Bertness, L. E. Stanton, and I. A. Mendelssohn. 2005. Drought, snails, and large-scale die-off of southern US salt marshes. Science 310:1803-1806.
Suding, K. N., and R. J. Hobbs. 2009. Threshold models in restoration and conservation: a developing framework. Trends in Ecology and Evolution 24:271-279.

Touchette, B. W., and J. M. Burkholder. 2000. Review of nitrogen and phosphorus metabolism in seagrasses. Journal of Experimental Marine Biology and Ecology 250:133-167.

van de Koppel, J., P. M. J. Herman, P. Thoolen, and C. H. R. Heip. 2001. Do alternate stable states occur in natural ecosystems? Evidence from a tidal flat. Ecology 82:34493461 .

van der Heide, T., A. Smolders, B. Rijkens, E. H. van Nes, M. M. van Katwijk, and J. Roelofs. 2008. Toxicity of reduced nitrogen in eelgrass (Zostera marina) is highly dependent on shoot density and $\mathrm{pH}$. Oecologia 158:411-419. van der Heide, T., E. H. van Nes, G. W. Geerling, A. J. P. Smolders, T. J. Bouma, and M. M. van Katwijk. 2007. Positive feedbacks in seagrass ecosystems: implications for success in conservation and restoration. Ecosystems 10:13111322.

van der Heide, T., E. H. van Nes, M. M. van Katwijk, H. Olff, and A. J. P. Smolders. 2011. Positive feedbacks in seagrass ecosystems: evidence from large-scale empirical data. PLoS ONE 6:7.

van Katwijk, M. M., A. R. Bos, V. N. de Jonge, L. Hanssen, D. C. R. Hermus, and D. J. de Jong. 2009. Guidelines for seagrass restoration: importance of habitat selection and donor population, spreading of risks, and ecosystem engineering effects. Marine Pollution Bulletin 58:179-188.

van Katwijk, M. M., A. R. Bos, D. C. R. Hermus, and W. Suykerbuyk. 2010. Sediment modification by seagrass beds: muddification and sandification induced by plant cover and environmental conditions. Estuarine Coastal and Shelf Science 89:175-181.

van Katwijk, M. M., and D. C. R. Hermus. 2000. Effects of water dynamics on Zostera marina: transplantation experiments in the intertidal Dutch Wadden Sea. Marine Ecology Progress Series 208:107-118.

van Wesenbeeck, B. K., J. van de Koppel, P. M. J. Herman, J. P. Bakker, and T. J. Bouma. 2007. Biomechanical warfare in ecology; negative interactions between species by habitat modification. Oikos 116:742-750.

Volkenborn, N., S. I. C. Hedtkamp, J. E. E. van Beusekom, and K. Reise. 2007. Effects of bioturbation and bioirrigation by lugworms (Arenicola marina) on physical and chemical sediment properties and implications for intertidal habitat succession. Estuarine Coastal and Shelf Science 74:331-343.

Volkenborn, N., and K. Reise. 2006. Lugworm exclusion experiment: responses by deposit feeding worms to biogenic habitat transformations. Journal of Experimental Marine Biology and Ecology 330:169-179.

Wilson, W. H. 1991. Competition and predation in marine softsediment communities. Annual Review of Ecology and Systematics 21:211-241. 